SUBJECT AREAS:

BEHAVIOURAL ECOLOGY

PLANT ECOLOGY

Received

11 September 2014

Accepted

5 December 2014

Published

8 January 2015

Correspondence and requests for materials should be addressed to

S.-S.L. (shshliu@zju. edu.cn)

* These authors contributed equally to this work.

\section{Differential profiles of direct and indirect modification of vector feeding behaviour by a plant virus}

\author{
Wen-Bo He*, Jie Li* \& Shu-Sheng Liu
}

Ministry of Agriculture Key Laboratory of Agricultural Entomology, Institute of Insect Sciences, Zhejiang University, Hangzhou 310058, China.

Plant viruses interact with their insect vectors directly and indirectly via host plants, and this tripartite interaction may produce fitness benefits to both the vectors and the viruses. Our previous studies show that the Middle East-Asia Minor 1 (MEAM1) species of the whitefly Bemisia tabaci complex improved its performance on tobacco plants infected by the Tomato yellow leaf curl China virus (TYLCCNV), which it transmits, although virus infection of the whitefly per se reduced its performance. Here, we use electrical penetration graph recording to investigate the direct and indirect effects of TYLCCNV on the feeding behaviour of MEAM1. When feeding on either cotton, a non-host of TYLCCNV, or uninfected tobacco, a host of TYLCCNV, virus-infection of the whiteflies impeded their feeding. Interestingly, when viruliferous whiteflies fed on virus-infected tobacco, their feeding activities were no longer negatively affected; instead, the virus promoted whitefly behaviour related to rapid and effective sap ingestion. Our findings show differential profiles of direct and indirect modification of vector feeding behaviour by a plant virus, and help to unravel the behavioural mechanisms underlying a mutualistic relationship between an insect vector and a plant virus that also has features reminiscent of an insect pathogen.

M ost plant viruses are transmitted by insect vectors and thus depend on the behaviour and dispersal of their vectors to spread from plant to plant ${ }^{1-3}$. Plant viruses may thus evolve mechanisms to alter the behaviour of their vectors in favour of their own transmission and spread. Recent case studies with plant viruses show that virus infection of the vectors can directly alter their feeding behaviour and preference in ways favourable to the spread of viruses ${ }^{4,5}$. Moreover, plant viruses can modify the feeding behaviour of their vectors indirectly, via the alternations of biochemical, physiological and morphological features of host plants, with consequential changes in plant attractiveness, resistance and/or nutrition that may facilitate population increase of the vectors and in turn the epidemiology of the viruses ${ }^{6-10}$.

The whitefly Bemisia tabaci (Gennadius) (Hemiptera: Aleyrodidae) is a species complex consisting of over 30 morphologically indistinguishable species ${ }^{11-13}$. Whiteflies of this species complex damage crops directly through phloem feeding and indirectly through transmission of numerous begomoviruses (family Geminiviridae, genus Begomovirus) ${ }^{3,14-16}$. Some cryptic species of this complex, in particular the Middle East-Asia Minor 1 (MEAM1) and the Mediterranean (MED), formally referred to as the "B biotype" and " $Q$ biotype" respectively, have risen to global prominence in the past 30 years due to their rapid invasion into many new regions of the world ${ }^{12,17,18}$. In many cases, invasion and spread of MEAM1 and/or MED were soon followed by disease pandemics of begomoviruses ${ }^{14,19,20}$. As the tripartite interactions between viruses, vectors and plants are known to have important influences on the population dynamics of the organisms involved ${ }^{8,21}$, the implications of the interactions between begomoviruses, whiteflies and plants in whitefly invasion and begomovirus pandemics have attracted much attention in recent years $\mathrm{x}^{22,23}$.

Begomoviruses are exclusively transmitted by $B$. tabaci in a persistent, circulative manner, which requires sustained saliva secretion as well as sap ingestion by the whiteflies ${ }^{24,25}$. As persistently-transmitted plant pathogens, begomoviruses interact with the whitefly vectors at the cellular level during movement among tissues and organs ${ }^{3,26}$, with the potential to alter directly the physiology and behaviour of the vector ${ }^{27-29}$. In addition, a few studies have provided indications that some begomoviruses have evolved high levels of adaptation to whitefly cells and tissues, and may exhibit some characteristics of insect pathogen $s^{30-32}$. Like many other persistently-transmitted viruses, begomoviruses may also modify the physiology and behaviour of their whitefly vectors indirectly via alternation of plant characteristics ${ }^{10,23,33,34}$. In our laboratory, an earlier study with the whitefly MEAM1, 
Table 1 Non-phloem EPG parameters of non-viruliferous and viruliferous whiteflies probing cotton plants; time is presented in minutes

\begin{tabular}{|c|c|c|c|}
\hline Parameters & Non-viruliferous ( $\mathrm{n}=25$ ) & Viruliferous $(n=29)$ & $P^{a}$ \\
\hline $\begin{array}{l}\text { 1. Time prior to } 1^{\text {st }} \text { probe } \\
\text { 2. Number of probes } \\
\text { 3. Total probing time } \\
\text { 4. Number of } C \text { periods } \\
\text { 5. Total duration of } C \\
\text { 6. Average } C \text { duration, with pd but without } E 1, F \text { and } G \\
\text { 7. Number of probes prior to } 1^{\text {st }} \mathrm{El} \text { ( } 1^{\text {st }} \text { phloem contact) } \\
\text { 8. Number of probes prior to } 1^{\text {st }} \mathrm{E} 2 \\
\text { 9. Time prior to } 1^{\text {st }} \mathrm{E} 1 \text { (total time from start to phloem) } \\
\text { 10. Time from first probe to } 1^{\text {st }} \mathrm{El} \\
\text { 11. Total duration of } \mathrm{G} \\
\text { 12. Total duration of } F\end{array}$ & $\begin{aligned} 34.64 & \pm 13.32^{b} \\
30.95 & \pm 5.69 \\
107.40 & \pm 10.95 \\
32.94 & \pm 5.83 \\
72.49 & \pm 9.48 \\
2.64 & \pm 0.41 \\
22.36 & \pm 8.94 \\
23.45 & \pm 8.92 \\
249.50 & \pm 41.66 \\
98.84 & \pm 27.98 \\
23.36 & \pm 8.86 \\
27.90 & \pm 10.75\end{aligned}$ & $\begin{aligned} 25.21 & \pm 6.32 \\
68.03 & \pm 12.29 \\
99.53 & \pm 8.81 \\
69.06 & \pm 6.17 \\
52.46 & \pm 4.84 \\
0.98 & \pm 0.08 \\
25.38 & \pm 8.33 \\
26.38 & \pm 8.34 \\
310.8 & \pm 28.84 \\
231.5 & \pm 37.29 \\
38.91 & \pm 8.42 \\
45.06 & \pm 7.90\end{aligned}$ & $\begin{array}{r}0.476 \\
\mathbf{0 . 0 0 5} \\
0.507 \\
\mathbf{0 . 0 1 2} \\
0.132 \\
<\mathbf{0 . 0 0 1} \\
0.507 \\
0.590 \\
0.386 \\
\mathbf{0 . 0 1 8} \\
0.257 \\
0.139\end{array}$ \\
\hline
\end{tabular}

a $P$ values calculated using Mann-Whitney U-test; $P$ values in boldface are significant at $\alpha=0.05$.

bData are expressed as means \pm SEM.

Tomato yellow leaf curl China virus (TYLCCNV), and tobacco [Nicotiana tabacum L. (Solanaceae)] showed that the whitefly population increased at a substantially higher rate on virus-infected plants than on uninfected plants, and further demonstrated that the enhanced rate of population increase in the whitefly was due to a marked increase in fecundity and longevity via feeding on virusinfected plants, even though virus infection of the whitefly per se reduced its fecundity and longevity ${ }^{9}$. By integrating genomics, transcriptomics and metabolomics with insect performance measures, we then found that the alternation of plant characteristics was related to repression of jasmonic acid-mediated plant defence, particularly suppression of terpenoid synthesis ${ }^{35,36}$. Evidence of alternation of plant nutrition to the whitefly, as measured in terms of amino acid profiles, percentage of essential amino acids, and suger: amino acid ratio in the phloem sap, was not detected ${ }^{37}$. However, the whiteflies feeding on virus-infected plants were able to achieve a more balanced nutritional assimilation with proportionally more amino acids, particularly essential amino acids, even though virus-infection of the whiteflies per se caused them to assimilate a more imbalanced nutrition with proportionally more sugar ${ }^{37}$. Further genomic and molecular analyses indicated that whiteflies feeding on virus-infected plants exhibited reduction of detoxification activity, which was likely to attenuate energy cost and help to improve their primary metabolic activities $^{38}$. However, the behavioural mechanisms of the whitefly underlying the improvement of nutritional assimilation and performance are yet to be investigated.

In the present work, we first studied the feeding behaviour of TYLCCNV-infected (viruliferous) and uninfected (non-viruliferous) MEAM1 on cotton, a non-host of TYLCCNV, to investigate the direct effects of the virus on feeding activities of whitefly. We then studied the feeding behaviour of viruliferous whiteflies on virusinfected and uninfected tobacco plants, plus non-viruliferous whiteflies on uninfected tobacco, to disentangle the direct and indirect effects of the virus on whitefly feeding activities. We used the electrical penetration graph (EPG) to observe and record the behavioural elements of whiteflies feeding on various plants ${ }^{39}$. Our findings help to unravel the behavioural mechanisms underlying a mutualistic relationship between an insect vector and a plant virus that also has features reminiscent of an insect pathogen.

\section{Results}

EPG waveform patterns observed. In this study, we identified seven distinct waveforms from the EPG recordings we made. Waveform patterns were categorized as previously described ${ }^{27,40}$ : NP, nonprobing behaviour; C, intercellular stylet pathway; pd (potential drops), brief intracellular stylet punctures during the pathway phase (C); E1, salivation into phloem sieve elements; E2, ingestion of phloem sap from sieve elements; F, presumed penetration difficulties; and G, xylem sap ingestion.

Direct effects of TYLCCNV on feeding behaviour of whitefly. We conducted EPG recording of non-viruliferous whiteflies and viruliferous whiteflies feeding on cotton plants, with 25 and 29 replicates respectively.

Non-phloem phase EPG measurements (Table 1). Viruliferous whiteflies made significantly more probes than non-viruliferous whiteflies (Parameter 2), while time prior to $1^{\text {st }}$ probe and total probing time did not differ between the two treatments (Parameters 1 and 3 ). Viruliferous whiteflies had a higher number of pathway waveforms (Waveform C; Parameter 4) than non-viruliferous whiteflies. Although the total duration of waveform C (Parameter 5) did not differ between the two treatments, the average duration of waveform $\mathrm{C}$ (with pd but without El, F, and G) of non-viruliferous whiteflies was significantly longer than that of viruliferous whiteflies (Parameter 6). While number of probes prior to $1^{\text {st }}$ E1 (Parameter 7), number of probes prior to $1^{\text {st }}$ E2 (Parameter 8), time from start to $1^{\text {st }}$ E1 (Parameter 9), total duration of waveform G (Parameter 11), and total duration of waveform $F$ (Parameter 12) did not differ between the two treatments, non-viruliferous whiteflies took less than half the time to proceed from $1^{\text {st }}$ probe to $1^{\text {st }} \mathrm{E} 1$, i.e. salivation, compared to that of viruliferous whiteflies (Parameter 10).

Phloem phase EPG measurements (Table 2). In the phloem phase, while no significant differences were detected between the two treatments in the number of E1 periods (Parameter 1), average E1 duration (Parameter 2), total duration of E1 (Parameter 3), time from $1^{\text {st }}$ E1 to $1^{\text {st }}$ sustained E2 (Parameter 5), number of E2 periods (Parameter 6), total duration of E2 periods (Parameter 8), number of E phases (Parameter 9), and total duration of E phases (Parameter 10), viruliferous whiteflies took more than twice longer to proceed from $1^{\text {st }} \mathrm{E} 1$ to $1^{\text {st }} \mathrm{E} 2$ (Parameter 4 ) compared to non-viruliferous whiteflies, and the average duration of E2 (Parameter 7) of nonviruliferous whiteflies was three times that of viruliferous whiteflies.

Direct and Indirect effects of TYLCCNV on feeding behaviour of whitefly via host plant. We conducted EPG recoding of the following three treatments: (1) non-viruliferous whiteflies feeding on uninfected tobacco, (2) viruliferous whiteflies feeding on uninfected tobacco, and (3) viruliferous whiteflies feeding on TYLCCNVinfected tobacco, with 30,28 , and 24 replicates for treatments (1), (2) and (3) respectively.

Non-phloem phase EPG measurements (Fig. 1). The two-way ANOVA statistics presented in Table 3 show that whitefly virusinfection status exerted significant effect on the number of waveform 
Table 2 | Phloem EPG parameters of non-viruliferous and viruliferous whiteflies probing cotton plants; time is presented in minutes

Parameters

Non-viruliferous

Viruliferous

$P^{a}$

1. Number of El periods

$1.64 \pm 0.31^{\mathrm{b}}$

$3.25 \pm 0.96$

0.178

2. Average El duration

$2.49 \pm 1.08$

$4.09 \pm 1.92$

3. Total duration of $E 1$

$4.09 \pm 1.92$
$1.71 \pm 0.46$

4. Time from $1^{\text {st }} \mathrm{E} 1$ to $1^{\text {st }} \mathrm{E} 2$

$1.95 \pm 0.51$

0.528

$4.40 \pm 1.47$

$7.74 \pm 2.55$

0.145

$1.18 \pm 0.12$

$3.92 \pm 0.64$

0.026

5. Time from ${ }^{\text {st }} \mathrm{E} 1$ to $1^{\text {st }}$ sustained $\mathrm{E} 2$

6. Number of E2 periods

$6.39 \pm 2.02$

0.230

$88.31 \pm 15.70$

$2.75 \pm 0.80$

0.098

7. Average E2 duration

$27.60 \pm 8.54$

0.005

8. Total duration of E2 periods

$100.30 \pm 14.59$

$75.88 \pm 17.63$

0.529

$2.82 \pm 0.35$

10. Total duration of $E$ phases

$88.24 \pm 16.15$

$6.00 \pm 1.74$

0.193

$74.08 \pm 15.75$

0.650

a $P$ values calculated using Mann-Whitney U-test; $P$ values in boldface are significant at $\alpha=0.05$.

bData are expressed as means \pm SEM.

C periods (Parameter c; Fig. 1c); the plant virus-infection status exerted significant effects on six of the eight parameters examined, including time to $1^{\text {st }}$ probe (Parameter a; Fig. 1a), number of probes (Parameter b; Fig. 1b), number of C periods (Parameter c; Fig. 1c), average $\mathrm{C}$ duration (Parameter e; Fig. 1e), number of probes prior to $1^{\text {st }}$ E1 (Parameter g; Fig. 1g), and number of probes prior to $1^{\text {st }}$ E2 (Parameter h; Fig. 1h); and the interaction between the two variables exerted significant effects on the number of probes (Parameter b; Fig. 1b) and number of $C$ periods (Parameter c; Fig. 1c). The statistical analysis indicates clearly that virus-infection of the plant exerted remarkably stronger effects on whitefly feeding behaviour than the virus infection of the whitefly per se.

When viruliferous whiteflies were placed on virus-infected plant, their time prior to $1^{\text {st }}$ probe was 3-4 times that of non-viruliferous or viruliferous whiteflies placed on uninfected plants (Fig. 1a). On uninfected plants, the number of probes of viruliferous whiteflies was significantly higher than that of non-viruliferous whiteflies; in contrast, the number of probes of viruliferous whiteflies feeding on virus-infected plants was significantly reduced compared to that of non-viruliferous whiteflies feeding on uninfected plants and was reduced to less than half that of viruliferous whiteflies feeding on uninfected plants (Fig. 1b). Likewise, on uninfected plants the number of $\mathrm{C}$ periods of viruliferous whiteflies was significantly increased compared to that of non-viruliferous whiteflies, but the number of $\mathrm{C}$ periods of viruliferous whiteflies was significantly reduced when feeding on virus-infected plants (Fig. 1c). Viruliferous whiteflies feeding on virus-infected plants significantly increased the average duration of waveform $\mathrm{C}$ compared to the other two treatments (Fig. 1e). The data of Fig. $1 \mathrm{~g}$ and $1 \mathrm{~h}$ also indicate that virus infection of plants reduced the number of probes prior to $1^{\text {st }} \mathrm{E} 1$ and the number of probes prior to $1^{\text {st }} \mathrm{E} 2$, although mean values of the three treatments did not differ significantly, possibly due to the effects of interaction between the two variables.

Phloem phase EPG measurements (Fig. 2). Table 4 presents the twoway ANOVA statistics on the data of phloem phase EPG measurements of the three treatments. While the virus-infection status of the whitefly appeared to exert no significant influence, its effects on the total duration of $\mathrm{E} 2$ periods (Parameter $\mathrm{n}$ ) and time from $1^{\text {st }} \mathrm{E} 1$ to $1^{\text {st }}$ E2 (Parameter o) were approaching to significant levels $(P=0.074$ and $P=0.067$ respectively). The plant virus-infection status exerted significant effects on three of the eight parameters examined, including average duration of E2 (Parameter 1), total duration of E2 periods (Parameter $\mathrm{n})$, and total time from $1^{\text {st }} \mathrm{E} 1$ to $1^{\text {st }} \mathrm{E} 2$ (Parameter $\mathrm{o}$ ). Interaction of the two variables exerted a significant effect on the time from $1^{\text {st }}$ E1 to $1^{\text {st }} \mathrm{E} 2$ (Parameter o), and its effects on the total duration of $\mathrm{E} 2$ periods (Parameter $\mathrm{n}$ ) and the relative proportion of E1 on E2 (Parameter $\mathrm{p})$ were close to significant levels $(P=0.064$ and $P=0.077$ respectively). Similar to the pattern observed for the nonphloem phase EPG measurements above, virus-infection of the plant exerted remarkably stronger effects on the phloem phase EPG measurements of the whitefly than the virus infection of the whitefly per se.

The stronger effects of virus-infection of the plant than those of the virus infection of the whitefly are shown by the comparison of mean values of each of the various parameters between treatments (Fig. 2). The data in Fig. 21 indicate that when the whiteflies were feeding on tobacco, virus infection of the whitefly per se did not significantly increase the average duration of E2, but the infection of both the whitefly and the plant did. Likewise, the data in Fig. $2 \mathrm{n}$ indicate that virus infection of the whitefly per se did not significantly increase the total duration of E2, but the infection of both the whitefly and the plant did. In addition, the data in Fig. 2o indicate that virus infection of the whitefly per se did not significantly reduce the time from $1^{\text {st }} \mathrm{E} 1$ to $1^{\text {st }} \mathrm{E} 2$, but the infection of both the whitefly and the plant did.

\section{Discussion}

In this study, two sets of experiments were conducted. In the first set of experiments, we observed the feeding behaviour of TYLCCNVviruliferous and non-viruliferous whiteflies on cotton, a non-host of the virus. This set-up enabled us to exclude effects of the virus-infection of the plant ${ }^{41}$ and thereby discern the effects of virus-infection of the whitefly per se on the vector feeding behaviour. However, because the plant is a non-host of the virus, the elements of feeding behavior of the whiteflies observed on this plant may deviate from those on a host plant of the virus.

In the second set of experiments, we observed the feeding behaviour of TYLCCNV-viruliferous whiteflies on TYLCCNV-infected and uninfected tobacco, a host of TYLCCNV, plus a treatment of non-viruliferous whiteflies feeding on uninfected tobacco. We did not include a treatment of non-viruliferous whiteflies feeding on TYLCCNV-infected tobacco, because we knew that the non-viruliferous whiteflies would soon and mostly become TYLCCNVinfected during the course of the $8 \mathrm{~h}$ observation, as indicated by the virus-acquisition data with the same species by Jiu et al. ${ }^{19}$, and the treatment therefore would not be valid to serve the purpose as intended. Other studies with Tomato yellow leaf curl virus (TYLCV) have shown that, once taken up by the whitefly via sap ingestion, the virions can complete their travel loop along the circulative transmission pathway in the vector and reach the salivary glands in a few hours, and the whitefly becomes infective in as short a period as $8 \mathrm{~h}^{42,43}$. We also expected some complication from the treatment of TYLCCNV-infected whiteflies on uninfected plants, because the uninfected plants might become infected with TYLCCNV during the course of the $8 \mathrm{~h}$ observation. To help design the treatments, we conducted a preliminary virus transmission trial with one viruliferous adult per plant and an inoculation access period of $8 \mathrm{~h}$, only $6.6 \%$ of the plants eventually became infected $(n=15)$. Studies on begomovirus-plant interactions have shown that, after the virions are secreted into the phloem tissue by the vector, they have to synthesize 
a

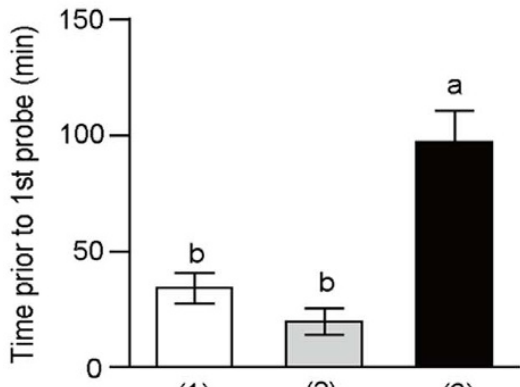

(1)

(3)

c

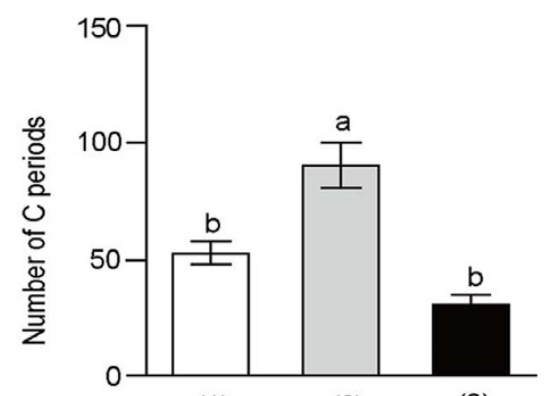

(1)

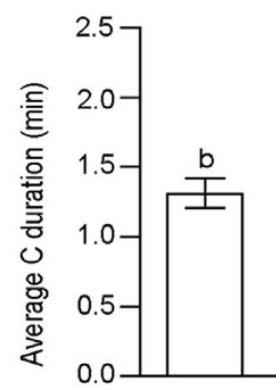

(1)

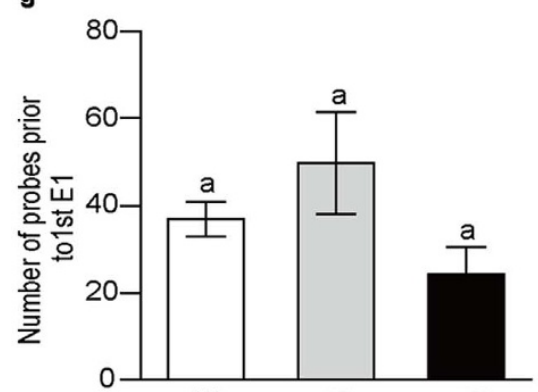

(1)

(2)
(2)

(3)

(3)

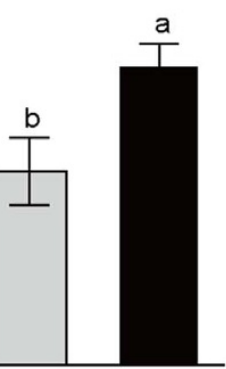

Treatment

b

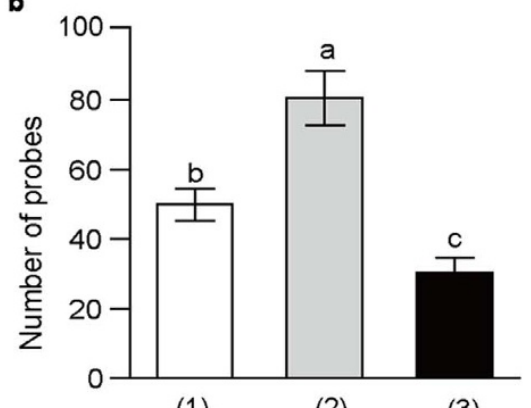

(1)

(2)

(3)

c

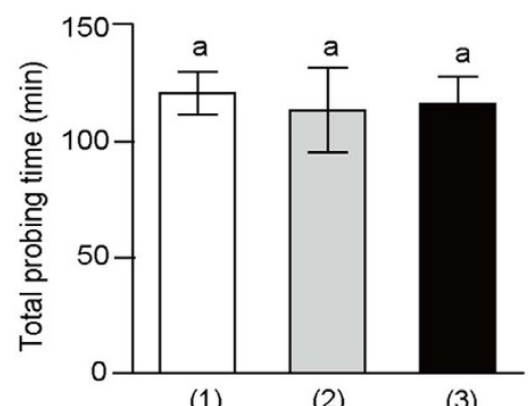

(1)

(2)

(3)

f

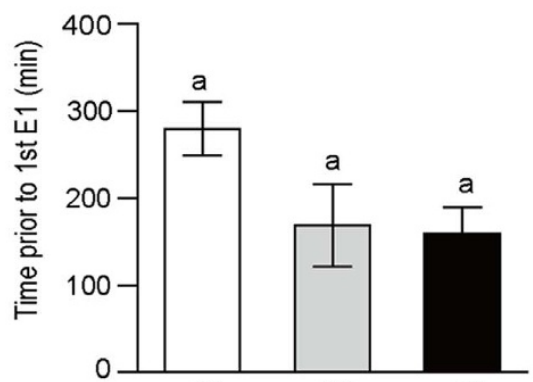

(1)

(2)

(3)

h

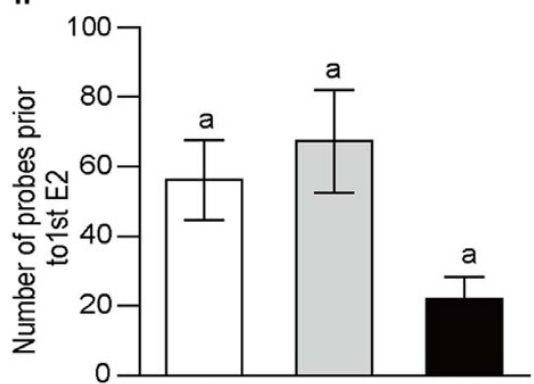

(1)

(2)

(3)

Figure 1 Effects caused by the presence of TYLCCNV on non-phloem parameters of feeding behaviour of whitefly. The three treatments include: (1) non-viruliferous adults feeding on uninfected tobacco, (2) viruliferous adults feeding on uninfected tobacco, and (3) viruliferous adults feeding on virus-infected tobacco. Panel labels correspond to parameter letters in Table 3; bars represent means \pm SEM; different letters above the bars indicate significant difference between treatments $(P<0.05$, LSD test $)$.

a sufficient amount of movement-associated proteins in the primary infected cells before they start the systemic, long-distance spread, within the plant; and the time taken from first virus-inoculation to systemic spread and multiplication usually would take several days, the duration of which depends on a number of variables, e.g. the species/strains of the whitefly, virus and plant involved, the virus load of inoculation (i.e., vector density, and virus quantity with each vector insect), and the plant growth stage ${ }^{44}$. With the same species of whitefly, begomovirus and plant as those used in this study, Jiu et al.
(2006) showed that with one viruliferous adult per plant, $30 \%$ of the plants still remained uninfected following an inoculation access period of $48 \mathrm{~h}$. Thus, the plants in this treatment would be largely uninfected by the virus during the $8 \mathrm{~h}$ period of observation, especially in regards to their effects on the feeding behaviour of the test vectors. Therefore, comparison between the three treatments in the second set of experiments (Figs. 1 and 2) would provide valid evidence to disentangle the direct and indirect effects of TYLCCNV on the feeding behaviour of MEAM1, and an integrated comprehension 


\begin{tabular}{|c|c|c|c|}
\hline Parameters $^{a}$ & \multicolumn{3}{|c|}{$P$ value ${ }^{a}$} \\
\hline $\begin{array}{l}\text { a. Time prior to } 1^{\text {st }} \text { probe } \\
\text { b. Number of probes } \\
\text { c. Number of } C \text { periods } \\
\text { d. Total probing time } \\
\text { e. Average } C \text { duration } \\
\text { f. Total time from start to } 1^{\text {st }} \mathrm{E} 1 \\
\text { g. Number of probes prior to } 1^{\text {st }} \mathrm{El} \\
\text { h. Number of probes prior to } 1^{\text {st }} \mathrm{E} 2\end{array}$ & $\begin{array}{l}0.746 \\
0.100 \\
\mathbf{0 . 0 0 2} \\
0.419 \\
0.604 \\
0.096 \\
0.601 \\
0.433\end{array}$ & $\begin{array}{r}<0.001 \\
<\mathbf{0 . 0 0 1} \\
<\mathbf{0 . 0 0 1} \\
0.305 \\
\mathbf{0 . 0 3 1} \\
0.761 \\
\mathbf{0 . 0 1 0} \\
\mathbf{0 . 0 0 4}\end{array}$ & $\begin{array}{l}0.573 \\
\mathbf{0 . 0 4 4} \\
\mathbf{0 . 0 0 7} \\
0.484 \\
0.750 \\
0.084 \\
0.732 \\
0.437\end{array}$ \\
\hline
\end{tabular}

aParameter codes correspond to panel labels in Figure 1; P values were calculated using two-way ANOVA with main effects of whitefly (viruliferous versus non-viruliferous), tobacco (virus-infected and uninfected), and their interaction. $P$ values in boldface are significant at $\alpha=0.05$.

of the data from the two sets of experiments would help further to discern the direct from the indirect effects of the virus on the feeding behaviour of the vector despite the complication that may arise from the use of a non-host of the virus in the first set of experiments.

While the feeding of MEAM1, either TYLCCNV-viruliferous or non-viruliferous, and on either virus-infected or uninfected plants, involves complex behaviour and process as shown by the EPG recordings, the analyses of the treatments in each of the two sets of experiments show clearly that virus-infection of the whiteflies per se mostly exerts adverse effects on their feeding, and in contrast, virusinfection of the host plants mostly offers benefits to their feeding and the indirect beneficial effects from the virus-infected plants largely surpass the direct adverse effects (Tables 1 and 2; Figs. 1 and 2). For example, in the first set of experiments, the number of waveform $\mathrm{C}$ periods in the viruliferous whiteflies was twice that of non-viruliferous whiteflies (Table 1), indicating that the whiteflies, once infected by TYLCCNV, experienced more difficulties in intercellular stylet pathway in order to reach the phloem. This type of obstacles in intercellular stylet pathway was also experienced by the viruliferous whiteflies feeding on uninfected tobacco in the second set of experiments; however, this obstacle was no longer experienced by viruliferous whiteflies once they fed on virus-infected tobacco, and in fact these viruliferous whiteflies reached the phloem tissue significantly sooner than the viruliferous adults feeding on uninfected plants, as indicated by their significantly lower number of waveform $\mathrm{C}$ periods (Fig. 1c). Similarly but not identically, in the first set of experiments, viruliferous whiteflies exhibited a significantly shorter average E2 duration than that of non-viruliferous whiteflies (Table 2, Parameter 7), indicating that the whiteflies, once infected by TYLCCNV, became less efficient in sustained sap ingestion. And in the second set of experiments, the average E2 duration was not significantly affected by the virus-infection of the whiteflies per se but became significantly enhanced once the viruliferous whiteflies fed on virus-infected plants (Fig. 2l).

The reminiscent pathogenic effects of TYLCCN on the feeding behaviour of MEAM1 observed here agree with those recorded from an earlier population study where TYLCCNV-infection of the MEAM1 whitefly per se reduced the vector's longevity and fecundity $^{9}$; as well as a nutritional assimilation-related study where the virus-infection of the whitefly per se rendered the vector to assimilate a more imbalanced nutrition ${ }^{37}$. Moreover, transcriptome analysis of TYLCCNV-viruliferous and non-viruliferous MEAM1 revealed that genes involved in the immune response, including all of the autophagy genes and most genes associated with lysosome function, in the whitefly are activated in viruliferous individuals, indicating that the whiteflies are mounting a defence against begomovirus invasion ${ }^{31}$.

The indirect, higher beneficial effects of TYLCCNV on the feeding behaviour of MEAM1 revealed from this study also agree with those reported from earlier population, physiological and behavioural studies, in which whiteflies that fed on virus-infected plants had higher survival and fecundity as well as higher rate of population increase, compared to non-viruliferous whiteflies feeding on uninfected plants ${ }^{9,37,45,46}$, and whiteflies were more attracted to virus-infected than uninfected plants ${ }^{47}$; as well as a nutritional assimilation-related study where whiteflies that fed on TYLCCNVinfected plants assimilated a more balanced nutrition ${ }^{37}$. These indirect benefits from the plants were shown to be related to repression of plant defence by the virus ${ }^{35,36}$. Indeed, MEAM1 whiteflies feeding on TYLCCNV-infected tobacco exhibited a reduced detoxification activity as indicated by the transcriptional profiles of the whiteflies feeding on TYLCCNV-infected and uninfected plants ${ }^{38}$.

Direct and indirect modifications of vector feeding behaviour are now known as a conserved trait among plant- as well as animalinfecting viruses, that evolved as a mechanism to facilitate virus transmission $^{4,7,27,48,49}$. Only a few studies have been conducted in this area for the interactions between begomoviruses and whiteflies in the B. tabaci species complex ${ }^{23}$. Liu et al. (2013) observed the feeding behaviour of MEAM1 as affected by the infection of TYLCV, and found that adults on virus-infected plants exhibited more active probing behaviour and had a higher number of feeding bouts than those on uninfected plants, and viruliferous adults fed more readily and spent more time salivating into sieve tube elements than nonviruliferous adults. Our current observations and records on MEAM1 feeding behaviour as affected by TYLCCNV essentially agree with those reported by Liu et al. (2013), and thus the two studies suggest that the two begomoviruses may exert similar influences on the feeding activities of MEAM1 in many situations. Several other studies have been conducted to observe the feeding behaviour of MED using various techniques including EPG and video recording $^{27-29,34}$. These studies demonstrate direct as well as indirect modifications of MED feeding behaviour by TYLCV, and generally they agree with each other to show that behavioural modifications, such as more sustained salivation and sap ingestion, confer benefits to virus transmission. Apparent disagreements, however, did occur between studies. For example, Moreno-Delafuente et al. (2013) reported that TYLCV-infection of MED induced arresting behaviour, as viruliferous adults remained motionless longer and moved more slowly than non-viruliferous adults ${ }^{27}$. In contrast, Hemayet Jahan et al. (2014) reported that TYLCV-infection of MED caused the adults to be more restless ${ }^{28}$. This kind of disagreements is not unexpected, because the interactions between a virus and its vectors may vary with the vector and plant species, even with different strains of the same spe$\operatorname{cies}^{23,33,50}$. In addition, the differences in techniques used between studies may result in apparent variation of behaviour ${ }^{27-29}$. Although some general patterns may exist, it is now also realized that the tripartite interactions in a given combination of species is dynamic and may vary with a number of internal and external factors such as disease progressing, the age of the vector, and the growth 
i

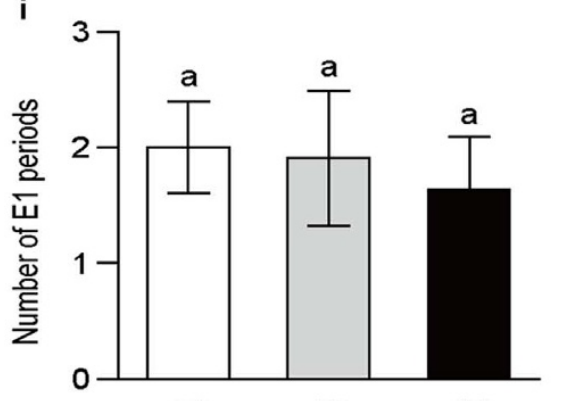

(1)

(2)

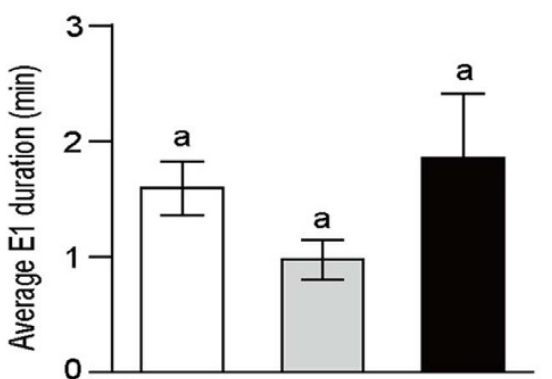

(1)

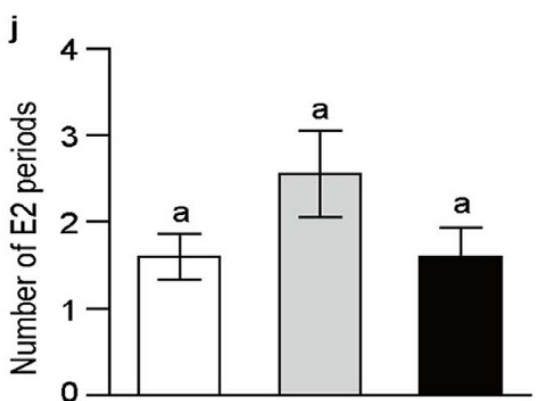

(1)
(2)
(3)

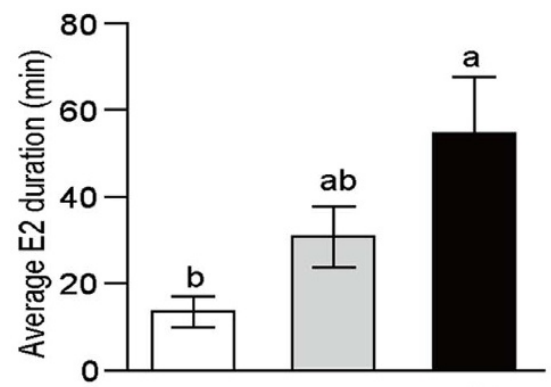

(1)

(2)

(3)

n

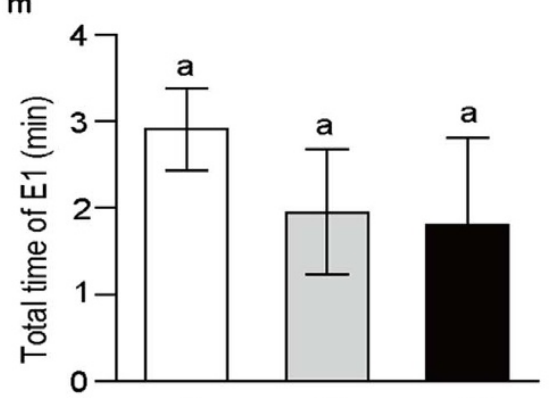

(1)

(2)

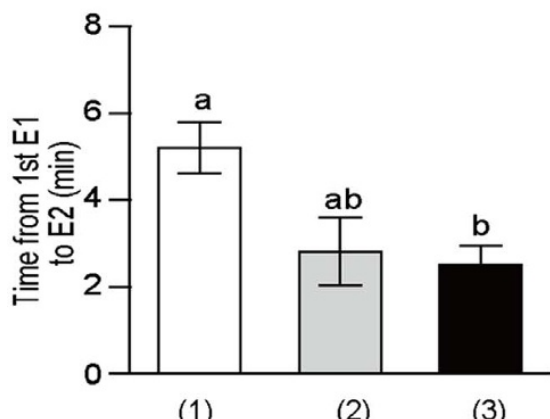

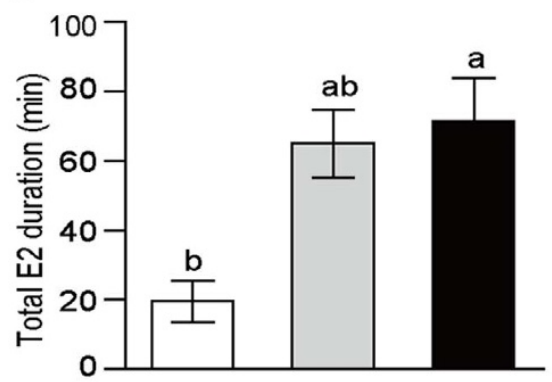

(1)

(3)

p

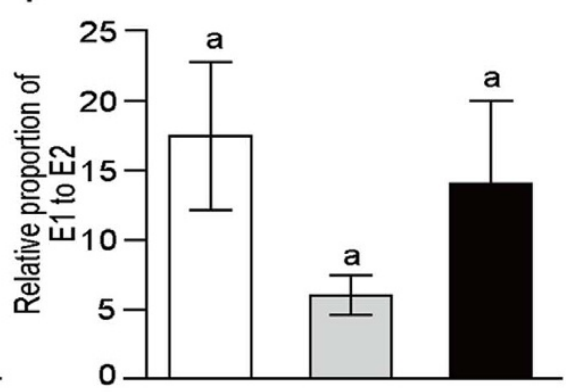

(1)

(2)
(3)

Treatment

Treatment

Figure $2 \mid$ Effects caused by the presence of the TYLCCNV on phloem parameters of feeding behaviour of whitefly. The three treatments include: (1) non-viruliferous adults feeding on uninfected tobacco, (2) viruliferous adults feeding on uninfected tobacco, and (3) viruliferous adults feeding on virus-infected tobacco. Panel labels correspond to parameter letters in Table 4; bars represent means \pm SEM; different letters above the bars indicate significant difference between treatments $(P<0.05$, LSD test $)$.

stage of the plant ${ }^{5}$. In addition, there may well be hidden players, such as endosymbionts of the organisms, whose roles in the tripartite interactions are barely understood so far ${ }^{51,52}$.

In conclusion, our current study, which employs EPG recordings to observe the whitefly feeding behaviour in detail, reveals differential profiles of direct and indirect modification of vector feeding behaviour by a begomovirus. While the direct modification exerts adverse effects on the vector, the indirect modification via the infection of host plant offers beneficial effects to the vector, and the indirect beneficial effects surpass the direct adverse effects and eventually improve vector fitness. Our results render better understanding of the pathogenic characters of a begomovirus on whiteflies and the indirect mutualism between the vector and virus via host plant. In addition, the new knowledge has the potential to help improve whitefly and begomovirus management. 
Table 4 | Statistical analysis of phloem EPG parameters of non-viruliferous and viruliferous whiteflies probing virus-infected and uninfected tobacco plants

Pvalue ${ }^{a}$

\begin{tabular}{|c|c|c|c|}
\hline Parameter $^{a}$ & Whitefly & Tobacco & Whitefly*Tobacco \\
\hline i. Number of El periods & 0.702 & 0.358 & 0.593 \\
\hline i. Number of E2 periods & 0.468 & 0.339 & 0.354 \\
\hline k. Average El duration & 0.427 & 0.993 & 0.355 \\
\hline I. Average E2 duration & 0.446 & 0.004 & 0.465 \\
\hline m. Total duration of $\mathrm{E} 1$ & 0.753 & 0.776 & 0.693 \\
\hline n. Total duration of E2 periods & 0.074 & 0.010 & 0.064 \\
\hline o. Time from $1^{\text {st }} \mathrm{E} 1$ to $1^{\text {st }} \mathrm{E} 2$ & 0.067 & 0.009 & 0.040 \\
\hline p. Relative proportion of $E 1$ on $E 2$ & 0.157 & 0.394 & 0.077 \\
\hline
\end{tabular}

aparameter codes correspond to panel labels in Figure 2; P values were calculated using two-way ANOVA with main effects of whitefly (non-viruliferous versus viruliferous), tobacco (virus-infected and uninfected), and their interaction. $P$ values in boldface are significant at $\alpha=0.05$.

\section{Methods}

Plants, virus and whitefly. Tobacco Nicotiana tabacum L. cv. NC89, a host plant of TYLCCNV, and cotton (Gossypium hirsutum cv. Zhe-Mian 1793), a non-host of TYLCCNV, were used. Clones of TYLCCNV with its satellite DNA molecules, also known as DNA $\beta$, were used as inocula for tobacco plants ${ }^{53}$. To obtain TYLCCNVinfected tobacco plants, plants at 3-4 true-leaf stage were inoculated with TYLCCNV and its associated DNA $\beta$ through agroinoculation as previously described ${ }^{53}$. Plants were then left to grow for 15 days, and infection status was determined by signs of leaf curling and subsequently confirmed by $\mathrm{PCR}^{53}$. All plants were maintained in separate insect-proof cages under natural lighting at $26 \pm 1{ }^{\circ} \mathrm{C}$ and $65 \pm 10 \%$ relative humidity.

The culture of Middle East-Asia Minor 1 (MEAM1) species (mtCOI GenBank accession no. GQ332577.1) of whitefly was maintained on cotton as previously described ${ }^{9}$. Viruliferous and non-viruliferous whiteflies were obtained by rearing the whitefly for two generations on virus-infected and uninfected tobacco plants respectively. In all treatments, we used only female adults, which were $3-5$ days postemergence and mated, in the EPG observation and recording, as previous studies have shown that females and males may differ in behaviour and efficiency of virus transmission ${ }^{43}$. Virus-infection was examined using the primers and PCR procedures as described by Cui et al. (2004).

Electrical penetration graph recording of whitefly feeding activities. An 8-channel DC-EPG device (EPG systems, Wageningen University, The Netherlands) was used to monitor the probing and feeding activities of viruliferous and non-viruliferous whitefly adults on plants. Before wiring the whitefly, plants were prepared and placed in an electrically grounded Faraday cage. The second or third youngest leaf of a plant was fixed on a stick vertically inserted into the pot and supported by a cardboard which is attached to the stick. To facilitate wiring, whitefly adults were maintained for 30 seconds in a finger-tube on an ice-bath. After the adults were immobilized, they were transferred to the cover of a glass dish filled with a layer of minced ice. Then, a gold wire ( $2 \mathrm{~cm}$ in length, $12.5 \mu \mathrm{m}$ in diameter) was attached to the pronotum of each adult with a small drop of water-based silver glue under the microscope. The opposite end of the gold wire was attached to a thin copper wire with silver glue. The wired adult was subsequently connected to the Giga-8 probe input and placed on the abaxial side of a plant leaf. The adults were left to adapt to the wiring for around $2 \mathrm{~h}$ before the start of EPGs recording. EPGs were continuously recorded for $8 \mathrm{~h}$ with a fresh adults and a new plant for each replicate of a treatment. Data acquisition was recorded by Stylet + for Windows software (EPG Systems, Wageningen University, The Netherlands) and data were analyzed with this software after data conversion.

Direct effects of virus infection on whitefly feeding. To reveal the direct effects of TYLCCNV on whitefly feeding, we observed and compared the EPGs of (1) viruliferous whitefly adults feeding on cotton plants, and (2) non-viruliferous whitefly adults feeding on cotton plants.

Direct and Indirect effects of virus on whitefly feeding via host plant. We observed the EPGs of (1) non-viruliferous adults feeding on uninfected tobacco, (2) viruliferous adults feeding on uninfected tobacco, and (3) viruliferous adults feeding on virusinfected tobacco. Comparison of the EPGs between the three treatments helps to reveal the indirect effects of virus on whitefly feeding via virus-infected host plants. We did not record EPGs of non-viruliferous adults on virus-infected tobacco, since whiteflies can acquire virus from plant in as short a period as a few minutes ${ }^{25}$.

Data analysis. Waveform patterns were categorized as previously described ${ }^{27,40}$. Seven distinct waveforms were identified in this study: NP; C; pd (potential drops); E1; E2; F and G (See Results section for explanation of terms).

The duration of each waveform was recorded and exported using software PROBE 3.4 (Wageningen University, The Netherlands). In total, 12 non-phloem phase parameters and 10 phloem phase parameters were calculated and compared between treatments. Parameters were calculated for each of the replicates in a treatment and then averaged to derive treatment-level means and standard errors. Prior to analysis, normality and homogeneity of variance were checked. Data were $\log 10$ transformed when it did not fit a normal distribution. All statistical analyses were done with IBM SPSS Statistics 20.0 (IBM Corp., Armonk, NY) and significant differences were tested at the 0.05 level.

For the two treatments with cotton plants designed to reveal the direct effects of virus infection on whitefly feeding, a Student's t-test was performed to analyze the data that followed a normal distribution, and the non-parametric Mann-Whitney Utest was used for comparison when normality was not achieved by $\log 10$ transformation.

For the three treatments with tobacco plants designed to reveal the direct as well as the indirect effects of virus on whitefly feeding, a two-way analysis of variance was performed to discern the effects of whitefly infection status (viruliferous versus nonviruliferous whitefly), plant infection status (virus-infected versus uninfected), and their interactions on whitefly feeding behaviour, including non-phloem phase and phloem phase parameters.

1. Fereres, A. \& Moreno, A. Behavioural aspects influencing plant virus transmission by homopteran insects. Virus Res. 141, 158-168 (2009).

2. Ng, J. C. \& Falk, B. W. Virus-vector interactions mediating nonpersistent and semipersistent transmission of plant viruses. Annu. Rev. Phytopathol. 44, 183-212 (2006).

3. Hogenhout, S. A., Ammar, E.-D., Whitfield, A. E. \& Redinbaugh, M. G. Insect vector interactions with persistently transmitted viruses. Annu. Rev. Phytopathol. 46, 327-359 (2008).

4. Ingwell, L. L., Eigenbrode, S. D. \& Bosque-Pérez, N. A. Plant viruses alter insect behavior to enhance their spread. Sci. Rep. 2, 578 (2012).

5. Rajabaskar, D., Bosque-Pérez, N. A. \& Eigenbrode, S. D. Preference by a virus vector for infected plants is reversed after virus acquisition. Virus Res. 186, 32-37 (2014).

6. Bosque-Pérez, N. A. \& Eigenbrode, S. D. The influence of virus-induced changes in plants on aphid vectors: insights from luteovirus pathosystems. Virus Res. 159, 201-205 (2011).

7. Mauck, K. E., De Moraes, C. M. \& Mescher, M. C. Deceptive chemical signals induced by a plant virus attract insect vectors to inferior hosts. Proc. Natl. Acad. Sci. USA 107, 3600-3605 (2010).

8. Belliure, B., Janssen, A., Maris, P. C., Peters, D. \& Sabelis, M. W. Herbivore arthropods benefit from vectoring plant viruses. Ecol. Lett. 8, 70-79 (2005)

9. Jiu, M. et al. Vector-virus mutualism accelerates population increase of an invasive whitefly. PloS ONE 2, e182 (2007).

10. Fang, Y. et al. Tomato yellow leaf curl virus alters the host preferences of its vector Bemisia tabaci. Sci. Rep. 3, 2876 (2013).

11. Boykin, L. M. \& De Barro, P. J. A practical guide to identifying members of the Bemisia tabaci species complex: and other morphologically identical species. Front. Ecol. Evol. 2, doi:10.3389/fevo.2014.00045 (2014).

12. De Barro, P. J., Liu, S. S., Boykin, L. M. \& Dinsdale, A. B. Bemisia tabaci: a statement of species status. Annu. Rev. Entomol. 56, 1-19 (2011).

13. Liu, S. S., Colvin, J. \& De Barro, P. J. Species concepts as applied to the whitefly Bemisia tabaci systematics: how many species are there? J. Integr. Agr. 11, 176-186 (2012).

14. Navas-Castillo, J., Fiallo-Olivé, E. \& Sánchez-Campos, S. Emerging virus diseases transmitted by whiteflies. Annu. Rev. Phytopathol. 49, 219-248 (2011).

15. Walker, G. P., Perring, T. M. \& Freeman, T. P. [Life history, functional anatomy, feeding and mating behavior] Bemisia: Bionomics and Management of a Global Pest [Stansly, P. A. \& Naranjo, S. E. (eds)] [109-160] (Springer 2010).

16. Naranjo, S. E., Castle, S. J., De Barro, P. J. \& Liu, S. S. [Population dynamics, demography, dispersal and spread of Bemisia tabaci] Bemisia: Bionomics and Management of a Global Pest [Stansly, P. A. \& Naranjo, S. E. (eds)] [185-226] (Springer, 2010). 
17. De Barro, P. \& Ahmed, M. Z. Genetic networking of the Bemisia tabaci cryptic species complex reveals pattern of biological invasions. PloS ONE 6, e25579 (2011).

18. $\mathrm{Hu}$, J. et al. An extensive field survey combined with a phylogenetic analysis reveals rapid and widespread invasion of two alien whiteflies in China. PloS ONE 6, e16061 (2011)

19. Jiu, M., Zhou, X. P. \& Liu, S. S. Acquisition and transmission of two Begomoviruses by the B and a non-B Biotype of Bemisia tabaci from Zhejiang China. J. Phytopathol. 154, 587-591 (2006).

20. Li, M., Hu, J., Xu, F. C. \& Liu, S. S. Transmission of Tomato yellow leaf curl virus by two invasive biotypes and a Chinese indigenous biotype of the whitefly Bemisia tabaci. Int. J. Pest Manage. 56, 275-280 (2010).

21. Stout, M. J., Thaler, J. S. \& Thomma, B. P. H. J. Plant-mediated interactions between pathogenic microorganisms and herbivorous arthropods. Annu. Rev. Entomol. 51, 663-689 (2006).

22. Colvin, J. et al. Host-plant viral infection effects on arthropod-vector population growth, development and behaviour: management and epidemiological implications. Adv. Virus Res. 67, 419-452 (2006).

23. Luan, J. B., Wang, X. W., Colvin, J. \& Liu, S. S. Plant-mediated whiteflybegomovirus interactions: research progress and future prospects. B. Entomol. Res. 104, 267-276 (2014)

24. Ghanim, M. A review of the mechanisms and components that determine the transmission efficiency of Tomato yellow leaf curl virus (Geminiviridae; Begomovirus) by its whitefly vector. Virus Res. 186, 47-54 (2014).

25. Czosnek, H., Ghanim, M. \& Ghanim, M. The circulative pathway of begomoviruses in the whitefly vector Bemisia tabaci-insights from studies with Tomato yellow leaf curl virus. Ann. Appl. Biol. 140, 215-231 (2002).

26. Wang, L. L. et al. Expression and functional characterisation of a soluble form of Tomato yellow leaf curl virus coat protein. Pest Manage. Sci. 70, 1624-1631 (2014).

27. Moreno-Delafuente, A., Garzo, E., Moreno, A. \& Fereres, A. A plant virus manipulates the behavior of its whitefly vector to enhance its transmission efficiency and spread. PloS ONE 8, e61543 (2013).

28. Hemayet Jahan, S. M., Lee, G. S., Lee, S. \& Lee, K. Y. Upregulation of probing- and feeding-related behavioural frequencies in Bemisia tabaci upon acquisition of Tomato yellow leaf curl virus. Pest Manage. Sci. 70, 1497-1502 (2014).

29. Wang, Y. C. et al. Probing and feeding behaviors of the MED cryptic species of Bemisia tabaci (Gennadius) effected by TYLCV. Environ. Entomol. 35, 415-421 (2013; in Chinese with English summary).

30. Rubinstein, G. \& Czosnek, H. Long-term association of Tomato yellow leaf curl virus with its whitefly vector Bemisia tabaci: effect on the insect transmission capacity, longevity and fecundity. J. Gen. Virol. 78, 2683-2689 (1997).

31. Luan, J. B. et al. Global analysis of the transcriptional response of whitefly to Tomato yellow leaf curl China virus reveals the relationship of coevolved adaptations. J. Virol. 85, 3330-3340 (2011).

32. Czosnek, H. \& Ghanim, M. Back to basics: Are begomoviruses whitefly pathogens? J. Integr. Agr. 11, 225-234 (2012).

33. Mauck, K., Bosque-Pérez, N. A., Eigenbrode, S. D., De Moraes, C. M. \& Mescher M. C. Transmission mechanisms shape pathogen effects on host-vector interactions: evidence from plant viruses. Funct. Ecol. 26, 1162-1175 (2012).

34. Liu, B. M. et al. Multiple forms of vector manipulation by a plant-infecting virus: Bemisia tabaci and Tomato yellow leaf curl virus. J. Virol. 87, 4929-4937 (2013).

35. Zhang, T. et al. Begomovirus-whitefly mutualism is achieved through repression of plant defences by a virus pathogenicity factor. Mol. Ecol. 21, 1294-1304 (2012).

36. Luan, J. B. et al. Suppression of terpenoid synthesis in plants by a virus promotes its mutualism with vectors. Ecol. Lett. 16, 390-398 (2013).

37. Wang, J., Bing, X. L., Li, M., Ye, G. Y. \& Liu, S. S. Infection of tobacco plants by a begomovirus improves nutritional assimilation by a whitefly. Entomol. Exp. Appl. 144, 191-201 (2012)

38. Luan, J. B., Wang, Y. L., Wang, J., Wang, X. W. \& Liu, S. S. Detoxification activity and energy cost is attenuated in whiteflies feeding on Tomato yellow leaf curl China virus-infected tobacco plants. Insect Mol. Biol. 22, 597-607 (2013).

39. Jiang, Y. X., De Blas, C., Barrios, L. \& Fereres, A. Correlation between whitefly (Homoptera: Aleyrodidae) feeding behavior and transmission of Tomato yellow leaf curl virus. Ann. Entomol. Soc. Am. 93, 573-579 (2000).

40. Jiang, Y. et al. Probing and feeding behavior of two distinct biotypes of Bemisia tabaci (Homoptera: Aleyrodidae) on tomato plants. J. Econ. Entomol. 92, 357-366 (1999).
41. Wang, J. et al. Low frequency of horizontal and vertical transmission of two begomoviruses through whiteflies exhibits little relevance to the vector infectivity. Ann. Appl. Biol. 157, 125-133 (2010).

42. Czosnek, H. et al. Whiteflies: vectors, and victims (?), of geminiviruses. Adv. Virus Res. 57, 291-322 (2001)

43. Czosnek, H. [Interactions of Tomato yellow leaf curl virus with its whitefly vector] Tomato Yellow LeafCurl Virus Disease: Management, Molecular Biology, Breeding for Resistance [Czosnek, H. (ed)] [157-170] (Springer, 2007).

44. Wege, C. [Movement and localization of Tomato yellow leaf curl viruses in the infected plant] Tomato Yellow Leaf Curl Virus Disease: Management, Molecular Biology, Breeding for Resistance [Czosnek, H. (ed)] [185-206] (Springer 2007).

45. Guo, J. Y., Ye, G. Y., Dong, S. Z. \& Liu, S. S. An invasive whitefly feeding on a virusinfected plant increased its egg production and realized fecundity. PloS ONE 5, e11713 (2010).

46. Guo, J. Y. et al. Enhanced vitellogenesis in a whitefly via feeding on a begomovirusinfected plant. PloS ONE 7, e43567 (2012).

47. Pan, D., Li, Y. X., Luan, J. B., Liu, S. S. \& Liu, Y. Q. Olfactory responses of the whitefly Bemisia tabaci and its parasitoid Eretmocerus hayati to tobacco infected by the Tomato yellow leaf curl China virus. Chinese Journal of Applied Entomology 50, 60-66 (2014; in Chinese with English summary).

48. Stafford, C. A., Walker, G. P. \& Ullman, D. E. Infection with a plant virus modifies vector feeding behavior. Proc. Natl. Acad. Sci. USA 108, 9350-9355 (2011).

49. Kenney, J. \& Brault, A. The role of environmental, virological and vector interactions in dictating biological transmission of arthropod-borne viruses by mosquitoes. Adv. Virus Res. 89, 39-83 (2014).

50. Liu, J., Zhao, H., Jiang, K., Zhou, X. P. \& Liu, S. S. Differential indirect effects of two plant viruses on an invasive and an indigenous whitefly vector: implications for competitive displacement. Ann. Appl. Biol. 155, 439-448 (2009).

51. Palukaitis, P., Groen, S. C. \& Carr, J. P. The Rumsfeld paradox: some of the things we know that we don't know about plant virus infection. Curr. Opin. Plant Biol. 16, 513-519 (2013)

52. Oliver, K. M. \& Martinez, A. J. How resident microbes modulate ecologicallyimportant traits of insects. Curr. Opin. Insect Sci. 4, 1-7 (2014).

53. Cui, X. F., Tao, X. R., Xie, Y., Fauquet, C. M. \& Zhou, X. P. A DNA $\beta$ associated with Tomato yellow leaf curl China virus is required for symptom induction. J. Virol. 78, 13966-13974 (2004).

\section{Acknowledgments}

This study was financially supported by the National Natural Science Foundation of China (Project No.: 31390421, 31321063), and Agricultural Research Programme of Guangdong Province China (Project No.: 2012A020200015).

\section{Author contributions}

S.S.L. and W.B.H. conceived and designed the research. W.B.H. and J.L. conducted the experiments and analyzed the data under supervision by S.S.L. W.B.H., J.L. and S.S.L. interpreted the results and wrote the paper.

\section{Additional information}

Competing financial interests: The authors declare no competing financial interests.

How to cite this article: He, W.-B., Li, J. \& Liu, S.-S. Differential profiles of direct and indirect modification of vector feeding behaviour by a plant virus. Sci. Rep. 5, 7682; DOI:10.1038/srep07682 (2015)

This work is licensed under a Creative Commons Attribution-NonCommercialNoDerivs 4.0 International License. The images or other third party material in this article are included in the article's Creative Commons license, unless indicated otherwise in the credit line; if the material is not included under the Creative Commons license, users will need to obtain permission from the license holder in order to reproduce the material. To view a copy of this license, visit http:// creativecommons.org/licenses/by-nc-nd/4.0/ 